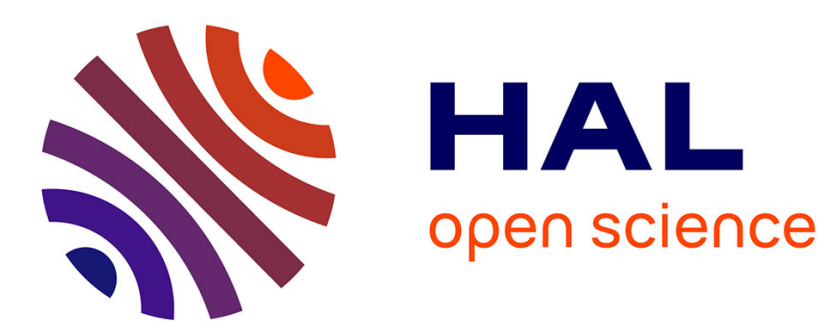

\title{
Twentieth-Century Hydrometeorological Reconstructions to Study the Multidecadal Variations of the Water Cycle Over France
}

\author{
Richard Bonnet, J. Boé, G. Dayon, E. Martin
}

\section{- To cite this version:}

Richard Bonnet, J. Boé, G. Dayon, E. Martin. Twentieth-Century Hydrometeorological Reconstructions to Study the Multidecadal Variations of the Water Cycle Over France. Water Resources Research, 2017, pp.17. 10.1002/2017WR020596 . hal-02606583

\section{HAL Id: hal-02606583 \\ https://hal.inrae.fr/hal-02606583}

Submitted on 16 May 2020

HAL is a multi-disciplinary open access archive for the deposit and dissemination of scientific research documents, whether they are published or not. The documents may come from teaching and research institutions in France or abroad, or from public or private research centers.
L'archive ouverte pluridisciplinaire HAL, est destinée au dépôt et à la diffusion de documents scientifiques de niveau recherche, publiés ou non, émanant des établissements d'enseignement et de recherche français ou étrangers, des laboratoires publics ou privés. 


\section{Water Resources Research}

\section{RESEARCH ARTICLE \\ 10.1002/2017WR020596 \\ Key Points: \\ Twentieth-Century Hydrometeorological Reconstructions to Study the Multidecadal Variations of the Water Cycle Over France}

- A method that combines long-term atmospheric reanalyses and

homogenized observations to obtain the forcing for hydrological modeling is presented

- Observed multidecadal river flows variations over France are generally mainly driven by climate variations - Other hydrological variables such as snow cover, evapotranspiration, and soil moisture also show multidecadal variations

Correspondence to:

R. Bonnet,

bonnet@cerfacs.fr

Citation:

Bonnet, R., Boé, J., Dayon, G., \& Martin, E. (2017). Twentieth-century hydrometeorological reconstructions to study the multidecadal variations of the water cycle over France. Water Resources Research, 53. https://doi.org/ 10.1002/2017WR020596

Received 15 FEB 2017

Accepted 30 AUG 2017

Accepted article online 13 SEP 2017

(c) 2017. American Geophysical Union. All Rights Reserved.

\author{
R. Bonnet1 ${ }^{(D)}$, J. Boé1 (D), G. Dayon 1,2 (D), and E. Martin, ${ }^{3,4}$ \\ ${ }^{1} \mathrm{CECl}$, Université de Toulouse, CNRS, Cerfacs, Toulouse, France, ${ }^{2}$ Pacific Climate Impacts Consortium, University of Victoria, \\ Victoria, BC, Canada, ${ }^{3}$ CNRM (Météo-France, CNRS), Toulouse, France, ${ }^{4}$ Irstea UR RECOVER, Aix-en-Provence, France
}

\begin{abstract}
Characterizing and understanding the multidecadal variations of the continental hydrological cycle is a challenging issue given the limitation of observed data sets. In this paper, a new approach to derive twentieth century hydrological reconstructions over France with an hydrological model is presented. The method combines the results of long-term atmospheric reanalyses downscaled with a stochastic statistical method and homogenized station observations to derive the meteorological forcing needed for hydrological modeling. Different methodological choices are tested and evaluated. We show that using homogenized observations to constrain the results of statistical downscaling help to improve the reproduction of precipitation, temperature, and river flows variability. In particular, it corrects some unrealistic long-term trends associated with the atmospheric reanalyses. Observationally constrained reconstructions therefore constitute a valuable data set to study the multidecadal hydrological variations over France. Thanks to these reconstructions, we confirm that the multidecadal variations previously noted in French river flows have mainly a climatic origin. Moreover, we show that multidecadal variations exist in other hydrological variables (evapotranspiration, snow cover, and soil moisture). Depending on the region, the persistence from spring to summer of soil moisture or snow anomalies generated during spring by temperature and precipitation variations may explain river flows variations in summer, when no concomitant climate variations exist.
\end{abstract}

\section{Introduction}

Internal climate variability is a large source of uncertainties in climate projections over the coming decades (Deser et al., 2010, 2012; Hawkins \& Sutton, 2009). In France, the uncertainties in precipitation changes related to internal variability are still as large as the uncertainties due to climate models in the middle of the 21st century (Terray \& Boé, 2013).

In a changing climate, multidecadal climate variations may temporarily reinforce or reverse the long-term impacts of climate change and have to be correctly taken into account by adaptation strategies. Unfortunately, the skill of current decadal prediction systems over the continent for lead-times greater than a few years is very small (Bellucci et al., 2015) and the properties of multidecadal variations are not necessarily always well captured by current climate models (Martin et al., 2014). Characterizing and understanding past observed multidecadal variations is a first necessary step to progress.

A recent study (Boé \& Habets, 2014) highlighted the existence of large multidecadal variations in French river flows. Multidecadal variations in large scale circulation in spring, likely driven by the Atlantic Multidecadal Variability (AMV; e.g., Kerr, 2000; Knight et al., 2005) cause important variations in spring precipitation and temperature, and, as a result, in spring river flows.

For some gauging stations, important river flows variations exist also in summer, but they are not associated with concomitant climate variations. Boé and Habets (2014) hypothesized that these variations might be due to hydrological processes related to water reservoirs with significant month-to-month or season-toseason autocorrelations (soil moisture and snow cover).

It is difficult to go further based only on observations. Long-term observations of river flows are rare and the other variables of the continental hydrological cycle (soil moisture, snow cover, and evapotranspiration) are virtually not observed on such long time scales. In addition, river flows observations may suffer from 
temporal inhomogeneities due to changes in measurement methods or to modifications of the river channel. River flows are also potentially impacted by nonclimatic anthropogenic influences, such as dams and water abstraction. It may therefore be difficult to disentangle the roles of climate variability and nonclimatic anthropogenic influences on the observed evolution of river flows. Long-term hydrological reconstructions from the early twentieth century based on hydrological modeling could be a promising way forward. The scarcity of meteorological observations in the first half of the twentieth century makes it difficult to rely on direct hydrological modeling with observed forcing (Minvielle et al., 2015). A preliminary step of reconstruction of the meteorological forcing is mandatory.

The recent release of two extended global atmospheric reanalyses has opened great opportunities in that context. The Twentieth Century Reanalysis (20CR) (Compo et al., 2011) from the National Oceanic and Atmospheric Administration (NOAA) and the European Reanalysis of the Twentieth Century (ERA20C) (Poli et al., 2016) from the European Center for Medium-Range Weather Forecasts (ECMWF) indeed cover at least the entire twentieth century. They can be downscaled, for example, with statistical methods typically used in climate change studies, to obtain the long-term high-resolution meteorological forcing for hydrological modeling (e.g., Caillouet et al., 2016).

A limitation of this approach is that the quality of the hydrological reconstructions strongly depends on the quality of the reanalyses. Only a limited set of observations is assimilated in the long-term reanalyses (sea level pressure and surface wind for ERA20C) and the density of the observation network strongly evolves with time. As a result, the realism of the low-frequency variations and trends in these reanalyses cannot be taken as granted. Not surprisingly, studies have highlighted potential unrealistic long-term trends or artificial temporal variations in long-term reanalyses (Krueger et al., 2013; Oliver, 2015). Additionally, this reconstruction approach is far from optimal, as it does not make use of all available observations. Indeed, even if they are scarce, long-term local precipitation and temperature observations exist and provide valuable information independent from that of long-term reanalyses.

A very interesting approach in that context is to combine the results of downscaled long-term reanalyses with local observations to derive the meteorological forcing, as in Minvielle et al. (2015) and Kuentz et al. (2015). This approach may correct the unrealistic long-term trends and low-frequency evolutions potentially due to reanalyses in the downscaling results, and help to recover a part of the local variability that cannot be captured by the statistical downscaling of long-term reanalyses alone.

In this study, a new method to reconstruct the meteorological forcing over France needed for hydrological modeling is presented. It is based on the results of a statistical downscaling method described in Dayon et al. (2015) applied to two long-term atmospheric reanalyses (20CR and ERA20C) and constrained by long-term homogenized observations of precipitation and temperature over France. A physically based hydrological model is then used to derive hydrological reconstructions over the entire France throughout the twentieth century.

This study has two main objectives. The first one is to describe and evaluate the reconstruction method, and to assess the added value of using local observations to constrain the results of statistical downscaling. The second one is to characterize the multidecadal variations over France that may exist in the variables of the continental hydrological cycle that are not well observed (e.g., snow cover, soil moisture, and evapotranspiration). We will also investigate the mechanisms responsible for the multidecadal variations of summer river flows noted by Boé and Habets (2014).

The data, models, and methods used in this study are presented in section 2. Section 3 describes the methodology developed to obtain the hydrometeorological reconstructions over France. These reconstructions are evaluated in section 4 focusing on the mean state, the temporal variability, including the low-frequency evolution, and the temporal stability in skill. The multidecadal variations in the hydrological cycle over France and the mechanisms behind the summer variations are then studied in section 5 . Finally, the conclusions of this work are sum up in section 6.

\section{Data, Models, and Methods}

\subsection{Observations}

For precipitation and temperature, monthly homogenized series over France from the Série Mensuelle de Réference (SMR, monthly series of reference) data set, developed by Météo-France (Moisselin et al., 2002), 


\section{QAGU Water Resources Research}

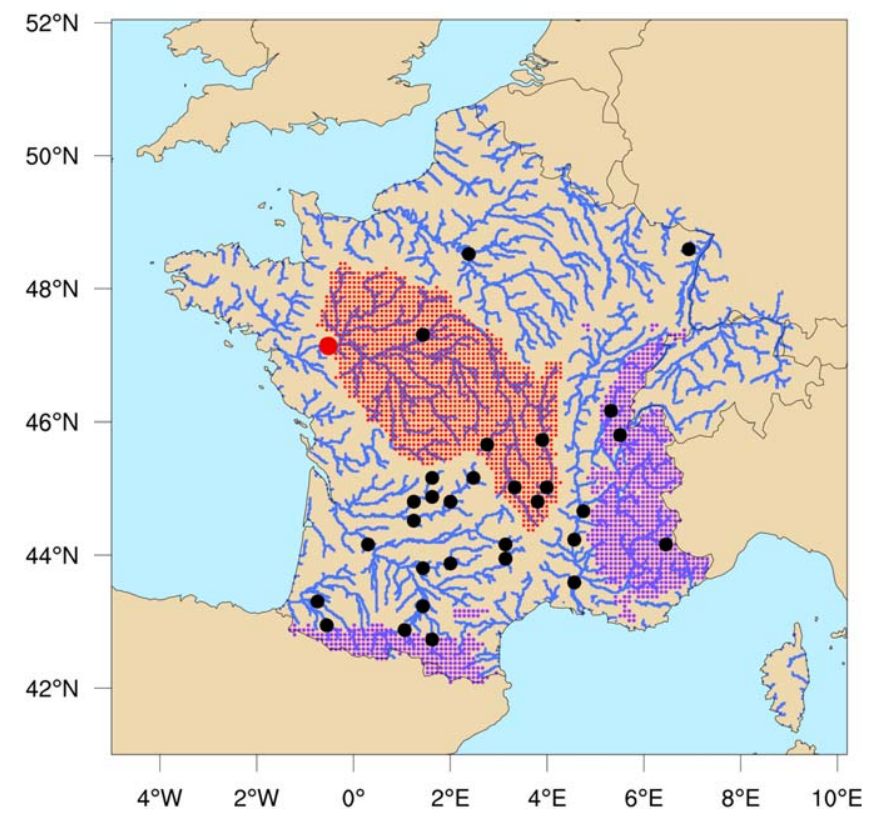

Figure 1. Location of the long-term gauging stations (circles) and simulated river network (blue lines). The two mountain regions (Pyrenees in the south of France and Alps in the east) studied in section 5.2 are shown in purple. The Loire at Montjean gauging station, studied in section 5.3 is shown with a red circle and the corresponding catchment is shown in red. are used. 310 stations are available for precipitation and 91 for temperature, from 1890 to 2006. The homogenization was intended to detect and correct potential homogeneity breaks related to changes in location or instrumentation. These monthly series therefore constitute a high-quality data set, well adapted to the study of long-term trends and low-frequency variability. These observations are used for the meteorological reconstructions (section 3) and for their assessment (section 4). A limitation of this data set in the context of our study is that the observations are not spatially homogeneous over France (as shown later in Figure 3).

Daily river flows at 32 gauging stations across France from the national HYDRO database (www.hydro.eaufrance.fr) are used. These stations have been selected in order to have at least 70 years of measurements with few missing values and to be simulated by the ISBA-MODCOU model (section 2.2). All the series start before 1935 and have a median (minimum) length of 95 (76) years. There are just a few stations in the North whereas the south-west corner of France is rather well covered (Figure 1). The majority of the gauging stations have a catchment size between 1,000 and $10,000 \mathrm{~km}^{2}$ and just a few exceed $50,000 \mathrm{~km}^{2}$.

Some of the stations are very likely directly influenced by human activities (e.g., dams and water abstraction). For example, regarding the Garonne river in south-western France, where irrigated agriculture is particularly important, the total water uptake for agriculture, industry and drinking water at the basin-scale is estimated at $7 \%$ of the discharge (Sauquet et al., 2009). Unfortunately such evaluations do not exist for all river basins, and in any case, we would need to know how these anthropogenic influences have evolved in time. Additionally, the river flows data set is not homogenized, and the series are therefore not necessarily free of measurement artifacts. The interpretation of the variations at any particular station must therefore be conducted carefully.

\subsection{The SAFRAN-ISBA-MODCOU Hydrological-Meteorological System}

The hydrological reconstructions are based on the physically based ISBA-MODCOU system. ISBA (Noilhan \& Planton, 1989) is a soil-vegetation-transfer model that computes the surface water and energy budget, and MODCOU (Ledoux et al., 1984) routes the surface runoff simulated by ISBA in the hydrographic network and computes the evolution of some aquifers (on the Rhône and Seine basins). The SAFRAN analysis (Durand et al., 1993), based on about 4,100 observations collected by Météo-France and an optimal interpolation algorithm, has been developed to provide the seven atmospheric variables (liquid and solid precipitation, incoming longwave and shortwave radiation fluxes, $10 \mathrm{~m}$ wind speed, $2 \mathrm{~m}$ specific humidity, and temperature) at the hourly time step on an $8 \mathrm{~km}$ grid necessary to force ISBA-MODCOU. SAFRAN data, described and evaluated in Quintana-Seguí et al. (2008) and Vidal et al. (2010), are available from 1958 to present. A previous version of ISBA-MODCOU forced by SAFRAN is described and evaluated against observations in Habets et al. (2008). In our study, a new version of ISBA-MODCOU is used, with the multilayer version of ISBA (Boone et al., 2000; Decharme et al., 2011, 2013), and a new subgrid treatment of high elevation points, to improve the simulation of snow. ISBA-MODCOU does not take into account nonclimatic anthropogenic influences (e.g., dams and water abstraction). No river flows observation is used to calibrate ISBA-MODCOU, except for the concentration times of MODCOU routing scheme. The simulated river flows variations on interannual and longer periods are therefore independent from the observed ones. This is important for our methodology: when a good similarity exists between simulated and observed river flows variations, we can conclude that (i) the modeling approach is successful and (ii) the observed variations are not due to measurement artifacts nor to nonclimatic anthropogenic influences, as they can be reproduced without calibration by a model that does not simulate them. It is not strictly impossible that error compensation leads to an artificial good match between observations and reconstructions, but this eventuality is much less likely. 


\subsection{Methods}

In order to extract from the interannual variations the multidecadal variations observed in precipitation, temperature and river flows over France, and likely caused by the AMV (Boé \& Habets, 2014), a Lanczos lowpass filter with a cutoff frequency of 20 years and 21 weights is used. No padding is applied: the first and last 10 years of the unfiltered time series are missing in the filtered series.

In order to avoid artificial skill when computing temporal correlations between the reconstructions and observations, the series are deseasonalyzed by removing the annual cycle. For daily series, a centered 31 day running average is first applied in order to limit the noise in the computed annual cycle. Then, the climatological average for each day of the year is calculated. For monthly series, the climatological average of each month is simply calculated.

In this paper, winter means December-January-February (DJF), spring means March-April-May (MAM), summer means June-July-August (JJA), and autumn means September-October-November (SON).

The skills of reconstructed precipitation, temperature, and after hydrological modeling, river flows, are analyzed. For the meteorological variables, to compare the results of the reconstructions (on the $8 \mathrm{~km}$ SAFRAN grid) to station observations, the nearest grid point to each station is used. The results for river flows are likely more informative than those for precipitation and temperature, as no river flows information is used in the reconstruction process. The river flows from the reconstructions and observations are therefore independent (see discussion in section 2.2). Note however that the hydrological model is not perfect, and does not incorporate nonclimatic anthropogenic influences (such as dams). The differences between observed and reconstructed river flows therefore do not only reflect the real skill of the reconstruction methodology regarding the meteorological forcing.

\section{Development of the Hydrometeorological Reconstructions}

Our first objective is to develop accurate hydrological reconstructions over France starting from the beginning of the twentieth century thanks to hydrological modeling. As a first step, we need to obtain the meteorological forcing suitable for hydrological modeling, even in the early twentieth century when observations are very sparse. Long-term atmospheric reanalyses such as 20CR (Compo et al., 2011) and ERA20C (Poli et al., 2016) are a useful source of information in this context. These reanalyses are based on global atmospheric models, using observed sea surface temperatures and sea-ice conditions as boundary conditions, and with the assimilation of a limited set of observations. In 20CR, only surface and/or sea level pressure are assimilated. Surface marine winds are additionally assimilated in ERA20C. 20CR has a horizontal resolution close to $1.875^{\circ} \times 1.875^{\circ}$, with 28 vertical levels. The horizontal resolution of ERA20C is approximately of $125 \mathrm{~km}$, with 91 vertical levels. The V2 version of 20CR used in this work is available from 1871 to 2012. ERA20C data are available from 1900 to 2010.

It is possible to use statistical downscaling (SD) to derive from the reanalyses the necessary high-resolution meteorological forcing (Caillouet et al., 2016). As said in the introduction, this approach has some limitations. In particular, unrealistic long-term trends and low-frequency variations may exist in the reanalyses, with likely impacts on the reconstructions. As an illustration, the long-term evolution of precipitation and temperature over France in 20CR, ERA20C and in the homogenized observations are shown in Figure 2. A strong unrealistic negative trend in 20CR precipitation is seen (Figure 2a), and unrealistic low-frequency variations in temperature are seen in both reanalyses (Figure $2 b$ ).

Unrealistic long-term trends in precipitation and/or temperature are very likely to also exist after downscaling, even if precipitation and/or temperature are not used as predictors in the SD method (as demonstrated later in Figure 6). Moreover, the simple SD approach is far from optimal: even if local observations are scarce in the early twentieth century, they may still provide very useful information in complement to long-term reanalyses. In this study, we therefore propose an alternative approach that combines the information from long-term reanalyses and local observations, as Kuentz et al. (2015) and Minvielle et al. (2015). The homogenized observations described in section 2.1 are used in the objective to obtain more realistic long-term evolutions.

Given data availability, we focus on the 1900-2005 period. The main idea is to use a stochastic statistical downscaling method to downscale ERA20C or 20CR and generate an ensemble of potential trajectories of 


\section{QAGU Water Resources Research}
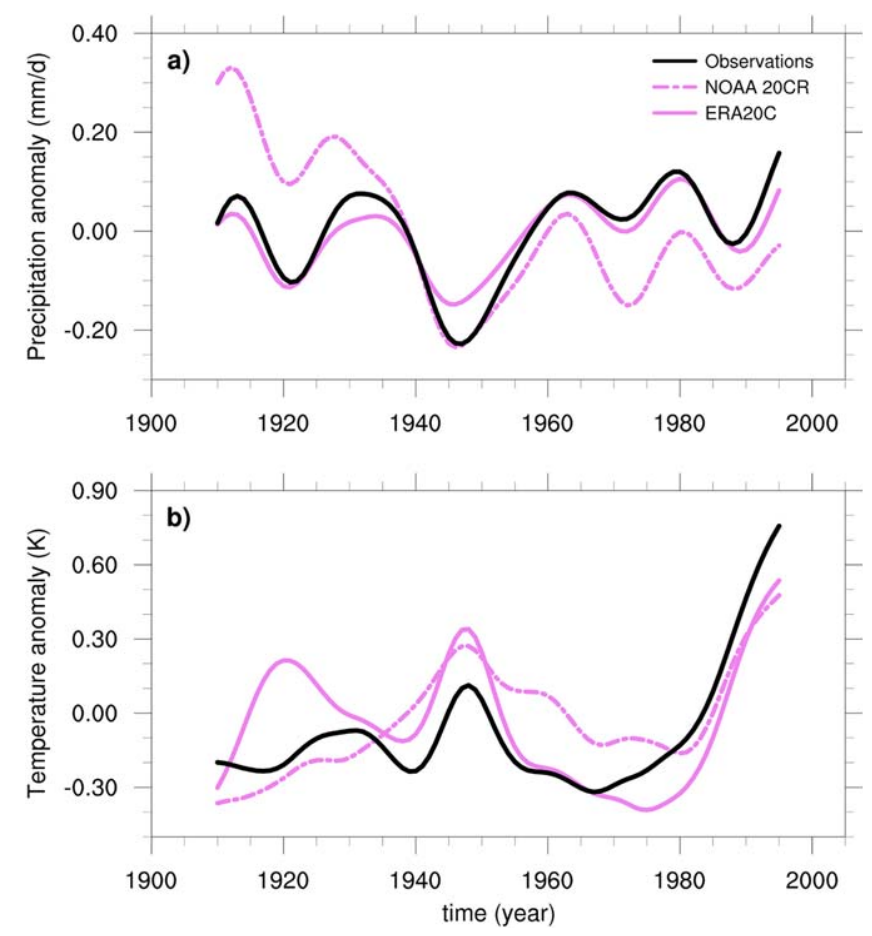

Figure 2. Annual low-pass filtered anomalies averaged over France of (a) precipitation $(\mathrm{mm} / \mathrm{d})$ and $(\mathrm{b})$ temperature $(\mathrm{K})$. The reference period is 1900-2005. Black: homogenized observations. Pink: reanalyses. Dashed line: 20CR. Solid line: ERA20C. local precipitation and temperature over France. Then, monthly homogenized observations are used to select the best trajectory among them. This approach is similar in philosophy to the methodology used by Goosse et al. (2006) in a different context.

The SD method developed by Dayon et al. (2015) to study the future changes in the continental hydrological cycle over France is used. The downscaling method is based on the analog method (Lorenz, 1969; Obled et al., 2002) at the daily time step. The analog method is based on the idea that if the large scale atmospheric states (e.g., large scale circulation over the North-Atlantic) of 2 days are close, then the high-resolution local variables of interest (e.g., precipitation over France) are also close. Five predictors are used to characterize the large scale atmospheric states: sea level pressure, $2 \mathrm{~m}$ temperature, Total Totals Index, module of moisture flux at $850 \mathrm{hPa}$, specific humidity at $850 \mathrm{hPa}$. The Total Totals Index is a simple indicator of atmospheric stability, defined as follows: $\Pi \mathrm{TI}=\left(\mathrm{Ta}_{850}-\right.$ $\left.\mathrm{Ta}_{500}\right)+\left(\mathrm{Td}_{850}-\mathrm{Ta}_{500}\right)$, where $\mathrm{Ta}_{850}$ and $\mathrm{Ta}_{500}$ are, respectively, the air temperature at 850 and $500 \mathrm{hPa}$ and $\mathrm{Td}_{850}$ is the dew point temperature at $850 \mathrm{hPa}$. For each day $D_{x}$ of the reconstruction period (1900-2005), we search the day (the so-called analog day) $D_{a}$ in the learning period (19792010) with the most similar large scale atmospheric state (as characterized by the five predictors). The observed variables of interest over France of the analog day $D_{a}$ are finally use as an estimate of the local state for the day $D_{x}$. SAFRAN variables are used as observations. This approach allows to obtain all the variables necessary for hydrological modeling over France on the SAFRAN grid from 1900 to 2005.

For the present work, this SD method has been slightly modified. For each day of the reanalysis to be downscaled, the 10 best analog days on the learning period are selected, rather than the single best analog day as described above. Thanks to this modification, an ensemble of potential trajectories of the local variable of interest over France (e.g., precipitation) can be created. Each day of the reconstruction period independently, one of the corresponding 10 analogs is randomly selected. This process can be repeated multiple times in order to obtain multiple trajectories. In practice, 5000 trajectories are created. For example, we randomly choose one of the 10 analog days for 1 January 1900, 2 January 1900, 3 January 1900, etc., all the way until 31 December 2005. This represents one of the 5000 daily-scale trajectories. We then repeat this process 4,999 more times, each time randomly selecting one of the 10 analog days for each day of the 1900-2005 time series. Sensitivity tests have shown that using more than 5,000 trajectories do not improve significantly the realism of the reconstructions.

As each analog day corresponds to a date of the learning period, the 5,000 corresponding daily series of precipitation (and of temperature in a variant described below) for the 1900-2005 time period over France on the SAFRAN grid are obtained from SAFRAN, and the monthly averages are computed. Then, for each month of the reconstruction period, the spatial root-mean-squared errors (RMSE) between the 5,000 monthly maps of precipitation after regridding and observed homogenized precipitation over France at the few stations where they are available (SMR stations, section 2.1) are computed. Regridding consists in selecting the SAFRAN grid point the closer to each SMR station. Note that in order to give the same weight to the different stations, the series at each station are standardized before computing the spatial RMSE.

Two types of reconstructions are generated, one that only uses observed precipitation to constrain the results of stochastic SD, as described above, and another one that uses both observed precipitation and temperature. When both temperature and precipitation are used, the spatial RMSEs are computed for temperature as for precipitation. Then, the sum of the RMSEs corresponding to precipitation and to temperature is computed, after the temporal standardization of the series of RMSEs in order to give the same weight to both variables.

In the end, each month, the daily series of analog days among the 5,000 ones that corresponds to the monthly map of precipitation (or maps of precipitation and temperature) with the lowest RMSE compared 
to SMR observations is selected. With this procedure a daily series of analog days is obtained on the entire reconstruction period (1900-2005). This series is finally used to obtain from the SAFRAN data set in the learning period the seven atmospheric variables necessary to force the ISBA-MODCOU.

This approach allows the advantages of the analog method to be kept (reconstruction of all the variables necessary for hydrological modeling at the required spatial resolution while maintaining the spatial and intervariable physical consistencies), while also benefiting from the high-quality information provided by the monthly homogenized observations.

We did not try to constrain the SD results by daily observations for two reasons. First, daily homogenized precipitation and temperature series over France do not exist, and it remains a major challenge to develop homogenization methods to deal with daily variables, especially precipitation. Moreover, as the quality of analog days decreases rapidly with their rank (i.e., with their similarity with the target day, not shown), only a small number of analog days could be retained for each day of the reconstruction (10 in our case), which would greatly limit the possibility to find a very good match with daily observation maps. Using monthly averages to constrain the results of SD allows a very large sample of different monthly precipitation and temperature maps to be generated (5,000 in our case, all different), based on only 10 different analogs each day. Six meteorological reconstructions over the 1900-2005 period are produced: unconstrained SD of ERA20C and 20CR (ERA20Cr and 20CRr), precipitation-constrained SD of ERA20C and 20CR (ERA20Cp and 20CRp), and precipitation-constrained and temperature-constrained SD of ERA20C and 20CR (ERA20Cpt and 20CRpt). The six corresponding hydrological reconstructions are obtained with the ISBA-MODCOU system.

\section{Evaluation of the Reconstructions}

\subsection{Mean State and High-Frequency Temporal Variability}

First, we evaluate the capacity of the reconstructions to capture the variability and mean state of precipitation and temperature over France. As the homogenized long-term precipitation and temperature observations are used as constraints in the reconstruction methodology, they are not independent from the reconstructions results. Their spatial sampling is also poor over France. We therefore use in a first time both the long-term observations and the gridded SAFRAN data set to evaluate the reconstructions. For the sake of simplicity, the first diagnostics are shown only for the reconstruction based on ERA20C and constrained by observed precipitation and temperature (ERA20Cpt). Precipitations from the reconstruction are well temporally correlated with the SMR and SAFRAN precipitations (Figure 3a).

Smaller correlations are generally obtained in the southeast of France, despite the availability of many SMR stations to constrain the reconstructions there. This may be due to the fact that this region is difficult to deal with a statistical downscaling method for the entire France (Dayon et al., 2015), as the synoptic conditions leading to precipitation over this area are often very specific. Lower correlations with SAFRAN are also obtained in the Alps and Massif-Central, where no SMR observation exists (Figure 3a). Regarding temperature, large interannual correlations are generally obtained over France, even where no SMR station exists, except for a few spots, notably in the Alps. Except for these particular results, both for temperature and precipitation, no major decreases in correlations are seen in areas where no SMR observation exists (Figures 3a and $3 b)$.

The mean biases of the reconstruction relatively to SAFRAN are generally small and quite uniform over France, both for precipitation and temperature (Figures $3 c$ and $3 \mathrm{~d}$ ). However, at several stations for precipitation and at one for temperature, large biases relatively to SMR are seen. It is likely because the SMR stations are compared to the closest grid point of the $8 \mathrm{~km}$ grid of the reconstructions, which may be problematic in areas with sharp variations in orography. Interestingly, the comparison of the reconstructions with SAFRAN shows no increase in biases in areas where no SMR station exists to constrain the reconstructions. Figure 3 shows that, generally, the uneven and/or limited spatial distribution of the SMR observations is still sufficient to obtain satisfactory results in areas where no observation exists. Note that very similar results are obtained with the equivalent reconstruction based on 20CR (20CRpt, not shown).

The skill of the different hydrometeorological reconstructions is now compared, focusing on daily and monthly correlations with observations, for precipitation, temperature, and river flows. As noted in section 2.3, the variables are deseasonalized before computing the correlations. For precipitation and temperature, 


\section{QAGU Water Resources Research}
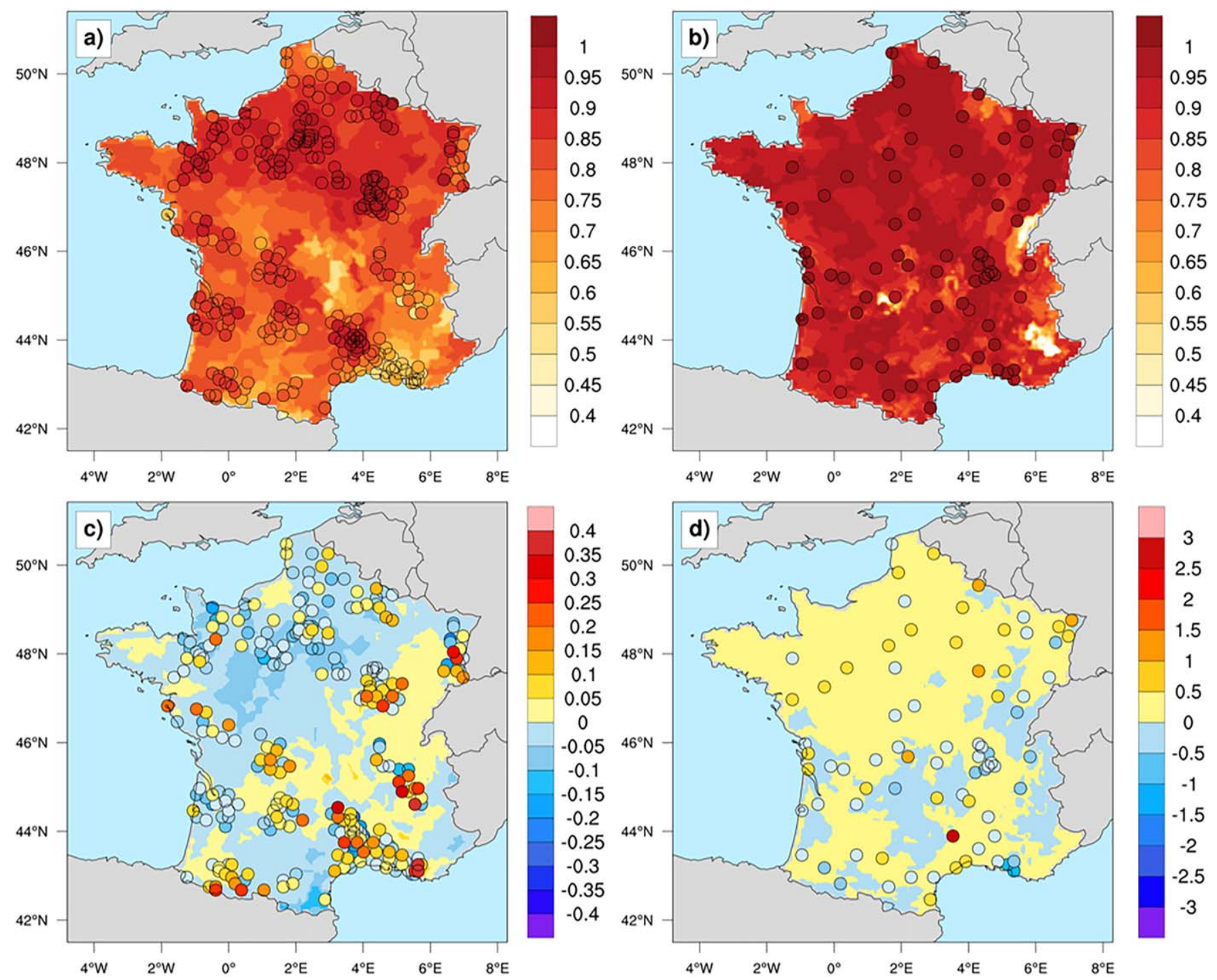

Figure 3. Interannual correlations between the ERA20Cpt reconstruction and SAFRAN (background) and between the ERA20Cpt reconstruction and the observa-

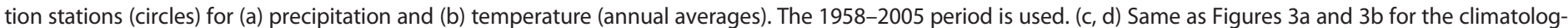
ical biases in Figure $3 c$ precipitation (relative) and in Figure $3 \mathrm{~d}$ temperature (K).

the SAFRAN data set is used as observational reference as the SMR observations are not available at the daily time step. In the unconstrained reconstructions, as in Dayon et al. (2015), the best analog day is always used. In the observationally constrained reconstructions, an analog day among the 10 best ones is chosen. As a relationship between the rank of the analog days and their adequacy exists (not shown), the observationally constrained reconstructions are expected to be less skillful than the direct results of SD for daily variations. For precipitation (Figure 4a), the daily correlations for the direct SD of ERA20C are slightly higher than the ones of observationally constrained reconstructions. It is not true for 20CR as all the reconstructions based on 20CR lead to very similar, and smaller, correlations. For temperature, a clear decrease in daily correlations is noted for observationally constrained reconstructions, especially when only precipitation is used as constraint (Figure 4c).

As expected, the interest of observationally constrained reconstructions becomes clear for monthly correlations. Much larger monthly correlations are obtained for all observationally constrained reconstructions for precipitation, with an increase in correlations generally close to 0.2 (Figure $4 \mathrm{~b}$ ). The best results are obtained when only precipitation is used as constraint, but the differences with the results of precipitation- 

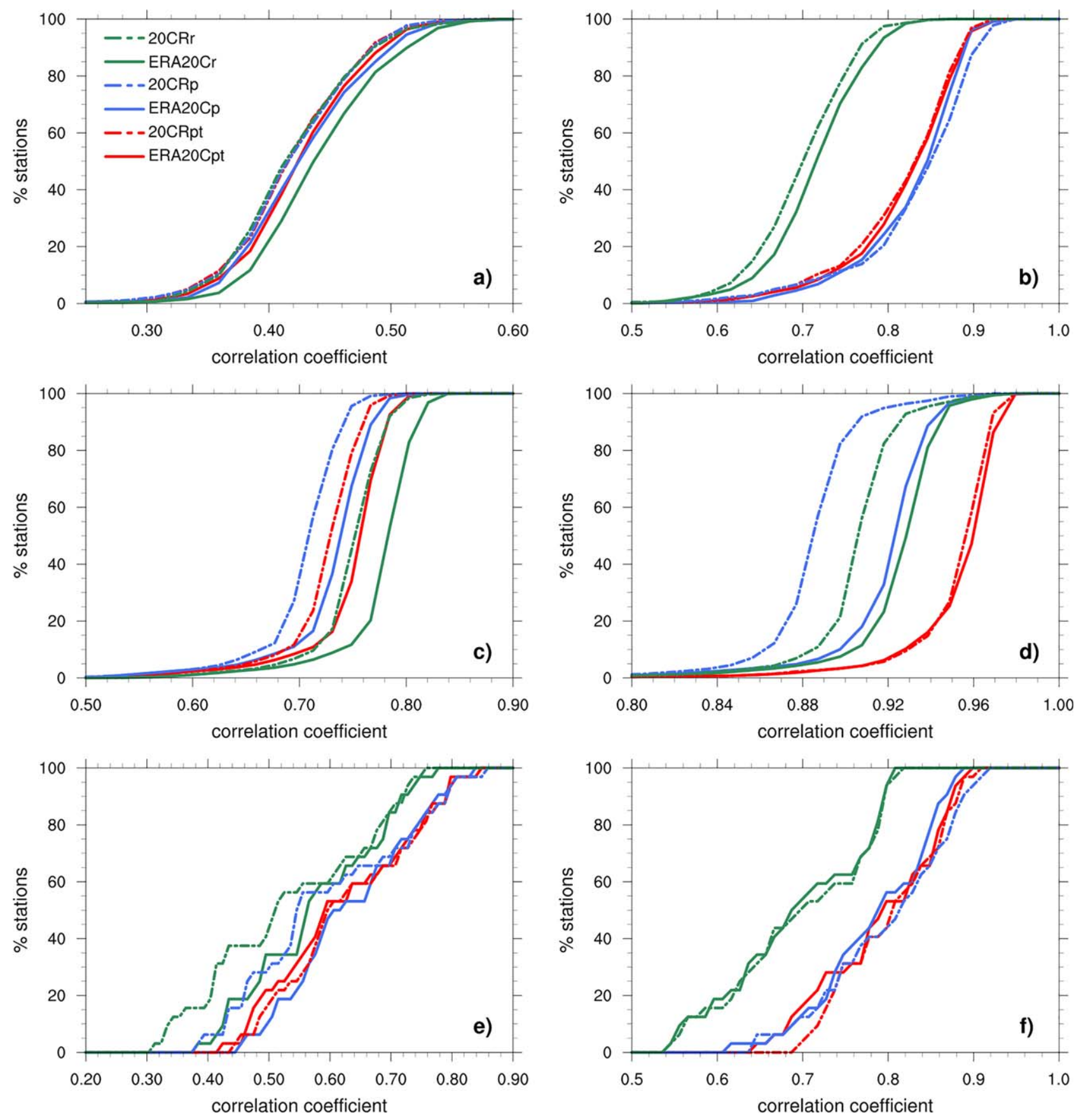

Figure 4. Cumulative density functions of the correlations between the reconstructions and the observations for $(a, b)$ precipitation, (c, d) temperature, (e, f) river flows for the $(a-c-e)$ daily and $(b-d-f)$ monthly averages. The series have been deseasonalyzed beforehand. For precipitation and temperature, the observations come from the SAFRAN data set. The correlations are computed at each grid point on the 1959-2005 period. For river flows, the correlations are computed for the gauging stations shown in Figure 1 on the longest possible period for each station. Unconstrained reconstructions in green, reconstructions constrained by precipitation in blue and reconstructions constrained by precipitation and temperature in red. Solid line: reconstructions derived from ERA20C. Dash-dotted line: reconstruction derived from $20 \mathrm{CR}$.

constrained and temperature-constrained reconstructions are very small. A large increase of the monthly correlations for temperature is obtained when temperature is also used as a constraint (Figure 4d).

As expected, the interest of observationally constrained reconstructions becomes clear for monthly correlations. Much larger monthly correlations are obtained for all observationally constrained reconstructions for precipitation, with an increase in correlations generally close to 0.2 (Figure 4b). The best results are obtained 
when only precipitation is used as constraint, but the differences with the results of precipitationconstrained and temperature-constrained reconstructions are very small. A large increase of the monthly correlations for temperature is obtained when temperature is also used as a constraint (Figure 4d).

Based on those results, using both temperature and precipitation to constrain the results of SD seems to be a good compromise. Using temperature in addition to precipitation leads to much realistic reconstructions for temperature, without an important decrease in skill regarding precipitation.

Very interestingly, better daily correlations are obtained for river flows with observationally constrained reconstructions (Figure 4e), despite the slight decrease in skill for precipitation and temperature noted previously. This rectification of high-frequency variability by lower frequencies variations is likely associated with slow-evolving hydrological variables (i.e., with a large month-to-month persistence) such as soil moisture and snow cover. Their evolutions are likely more realistic in the observationally constrained reconstructions, with an impact on daily river flows.

A very consistent increase in monthly correlations is seen when observations are used as constraint (between 0.1 and 0.15 ). The correlations are greater than 0.80 for half the stations with the observationally constrained reconstructions while this value of correlation is virtually never reached for the unconstrained reconstructions. Results for precipitation-only or temperature and precipitation-constrained reconstructions are very similar regarding river flows. The advantage of the better reproduction of temperature when temperature is used as a constraint in addition to precipitation noted in Figure $4 \mathrm{~d}$ does not necessarily translate to river flows for monthly averages.

The ERA20C reanalysis generally leads to higher monthly and daily correlations for all the variables for the unconstrained reconstructions. For the observationally constrained reconstructions, when a positive impact is expected (i.e., for monthly series), the results obtained with ERA20C and 20CR are very similar, showing that the constraint by observations tends to reduce the differences intrinsically associated with the reanalyses.

\subsection{Temporal Stability}

To study multidecadal variations with the reconstructions, a good temporal stability of their skill is required. It cannot be taken for granted as the skill of the long-term reanalyses may vary, notably because the density of the assimilated observations varies greatly in time (Compo et al., 2011; Poli et al., 2016).

To evaluate the temporal stability of the skill of the reconstructions, the monthly correlations between the reconstructions and observations are computed on three subperiods (Figure 5). For precipitation (Figure $5 \mathrm{a})$, the correlations are generally slightly smaller on the earlier periods whether or not observations are used as constraints, but overall, the skill is fairly homogeneous in time. For temperature (Figure 5b), the unconstrained reconstruction based on ERA20C shows a large decrease in correlations on the early twentieth century, while the $20 \mathrm{CR}$ unconstrained reconstruction is characterized by very similar correlations on the three periods. When the observations are used as constraints in the reconstructions, the correlations are very similar on the different subperiods, even with ERA20C. Regarding river flows (Figure 5c), the results are very similar on the three subperiods, independently of the reconstruction method.

The results described in this section demonstrate that the reconstructions, and in particular the ones using local observations as constraint, remain pertinent even in the early twentieth century.

\subsection{Low-Frequency Variability}

Unrealistic trends and/or multidecadal variations over France for 20CR precipitation and ERA20C and 20CR temperature have been noted in section 3. As expected, the statistical downscaling method cannot correct these issues, as similar evolutions are seen after downscaling (Figure 6). For precipitation, the observationally constrained reconstructions with $20 \mathrm{CR}$ are characterized by much more realistic trends and lowfrequency variations (Figure 6a). For temperature, realistic low-frequency variations are obtained only when temperature is used as a constraint in the reconstruction process (Figure 6b). These results clearly show that using homogenized temperature and precipitation to constrain the results of SD allows the errors due to reanalyses regarding long-term trends to be corrected to a large extent.

Now, the capacity of the hydrological reconstructions to capture decadal to multidecadal variations is studied. The correlations between observed and reconstructed variables are computed for the detrended low- 


\section{QAGU Water Resources Research}
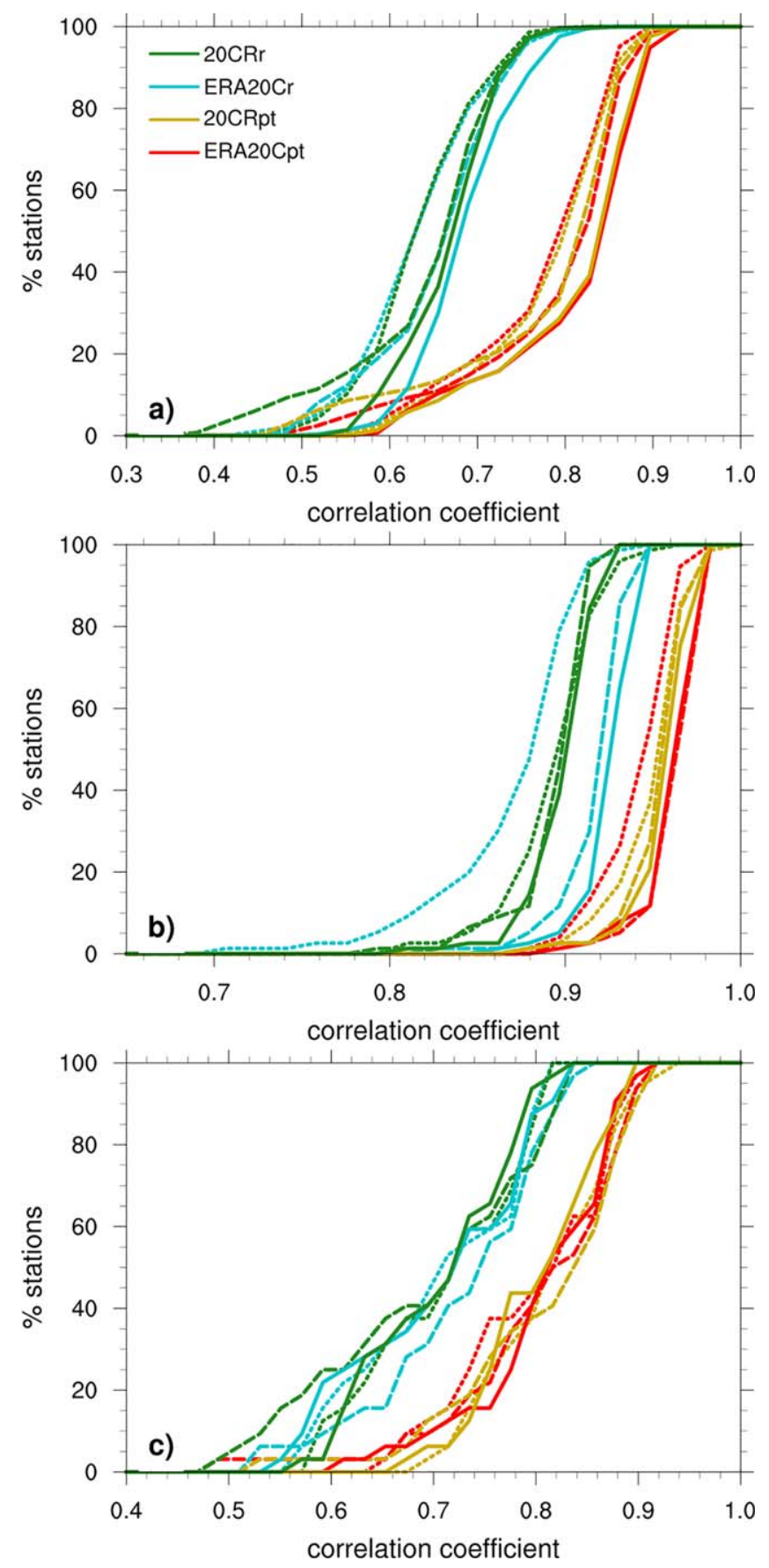

Figure 5. Cumulative density functions of the correlations for monthly averages between the observations and the reconstructions for (a) precipitation and (b) temperature on three different periods: 1900-1935 (short dashed line), 1935-1970 (long dashed line) and 1970-2005 (solid line). (c) Same as Figure 5a for river flows on the periods: 1920-1948 (short dash line), 1948-1976 (long dash line), and 1976-2004 (solid line). The series have been deseasonalyzed beforehand. For precipitation and temperature, the observations come from the SMR data set. For river flows, the correlations are computed for the gauging stations shown in Figure 1. Unconstrained reconstructions derived from ERA20C in turquoise and from $20 C R$ in dark green. Reconstructions constrained by precipitation and temperature derived from ERA20C in red and from 20CR in gold. pass filtered annual series (section 2.3 and Figure 7). For precipitation, observationally constrained reconstructions lead to much higher correlations (increase of 0.2 ). Note that the minimum correlation shown by the lower whisker is generally small, especially for the direct results of statistical downscaling (ERA20CR and 20CR, with a correlation close to 0). This is very likely an effect of the mismatch that exists between precipitation in the reconstruction on a $8 \mathrm{~km}$ by $8 \mathrm{~km}$ grid and the station observations to which they are compared to in Figure 7, in areas with sharp variations in orography. Note that such small correlations are only seen at a very few points (not shown).

For temperature, poor results are obtained with 20CR compared to ERA20C, when temperature is not used to constrain the reconstructions. Very high correlations for temperature (median close to 0.9 ) are obtained for both ERA20C and 20CR in the reconstructions constrained by temperature and precipitation. Here again, constraining the results of SD by observations tend to reduce the intrinsic differences due to the reanalyses.

Regarding river flows (Figure 7c), the improvement of the representation of low-frequency variations in the constrained reanalyses is smaller than for precipitation but still visible. Very high correlations are generally obtained for all the reconstructions. The best results are obtained with the reconstruction based on ERA2OC and using both temperature and precipitation as constraint.

The results presented in this entire section clearly show the interest of the approach proposed to combine data from long-term reconstructions through statistical downscaling and local observations for hydrological reconstructions. It allows the unrealistic trends due to the reanalyses in the direct results of SD to be corrected and more realistic monthly to multidecadal variations to be obtained.

\section{Multidecadal Variations of the Hydrological Cycle Over France}

\subsection{Characterization}

Boé and Habets (2014) have shown that large multidecadal variations in observed river flows over France exist in spring and are likely driven by climate variations (precipitation, and potentially temperature). For some stations, large variations are also observed in summer but they are not associated with concomitant climate variations, suggesting that hydrological processes, for example, involving soil moisture or snow are at play. These variables are not routinely observed, but the hydrological reconstructions allow the variations in all hydrological variables to be explored and the associated mechanisms to be studied.

First, the capacity of the reconstructions to correctly capture the multidecadal river flows variations in spring and summer is evaluated (Figure 8). In spring, very large correlations between the observations and the reconstructions are obtained for the great majority of stations (median correlation close to 0.9 ). The correlations in summer are also generally large, although less than in spring (median correlation close to 0.8 ). The observationally constrained reconstructions are more skillful in summer with a difference of correlations generally close to 0.2 compared to the results of direct downscaling. In spring, the advantage of observationally constrained reconstructions is still visible but smaller. For a very few gauging stations (or even a single station as in spring, not shown) very small correlations, as shown by the lower whiskers, are noted. The river flows observations are 

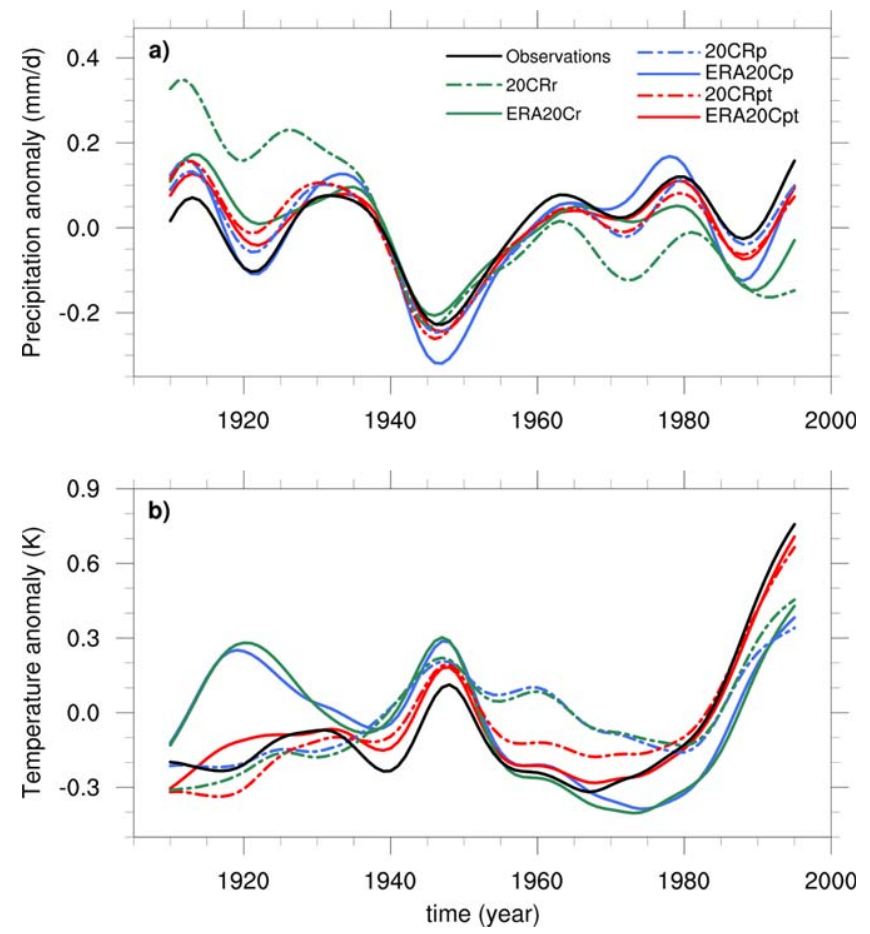

Figure 6. Annual low-pass filtered (a) precipitation and (b) temperature averaged over France. Black: observations. Green: unconstrained reconstruction. Blue: reconstructions constrained by precipitation-only. Red: reconstructions constrained by precipitation and temperature. The solid lines correspond to the reconstructions derived from ERA20C and the dash-dotted line those derived from 20CR. The reference period is 1900-2005. not homogenized, and the only criterion used for their selection is the length of the record. Some stations are very likely impacted by nonclimatic anthropogenic influences (e.g., dams or water abstraction), which are not taken into account in our hydrological model, hence the low correlations for a very few stations.

The good correlations between the observations and the reconstructions for the great majority of stations in terms of multidecadal variations confirm that the observed variations noted in Boé and Habets (2014) are not generally the results of an artifact of measurement or of nonclimatic anthropogenic influences, even for seasonal averages, when these potential influences are expected to have a larger imprint. Interestingly, despite the good correlations noted previously, the standard deviation of the low-pass filtered series from the reconstructions tends to be underestimated in spring, and somewhat underestimated in summer (Figures $8 \mathrm{c}$ and $8 \mathrm{~d}$ ). The same analysis for precipitation and temperature does not show a systematic underestimation of the amplitude of multidecadal variations in the reconstructions (not shown), suggesting that the representation of these variables is not responsible for the underestimation of the amplitude of multidecadal river flows variations. Different potential explanations may exist. (i) Hydrological feedbacks, not correctly captured by the hydrological model, may reinforce the variations initially caused by climate variations. (ii) Nonclimatic anthropogenic influences (e.g., dam management or irrigation practice) might reinforce the amplitude of climate-driven variations, through adaptive responses. (iii) Multidecadal variations in meteorological variables other than precipitation and temperature (e.g., humidity and solar radiation) may exist, influence river flows, and not be correctly captured by the reconstructions. Despite the underestimation of the amplitude of the multidecadal variations in spring, the previous results show that the reconstructions are useful to study the multidecadal variations in the continental hydrological cycle over France. As the multidecadal variations in river flows and precipitation from the reconstructions are generally consistent with those observed, and given the constraints imposed by the surface water budget, the previous results indirectly give a reasonable confidence in the realism of the other hydrological variables (e.g., soil moisture, evapotranspiration, and snow) in the reconstructions.

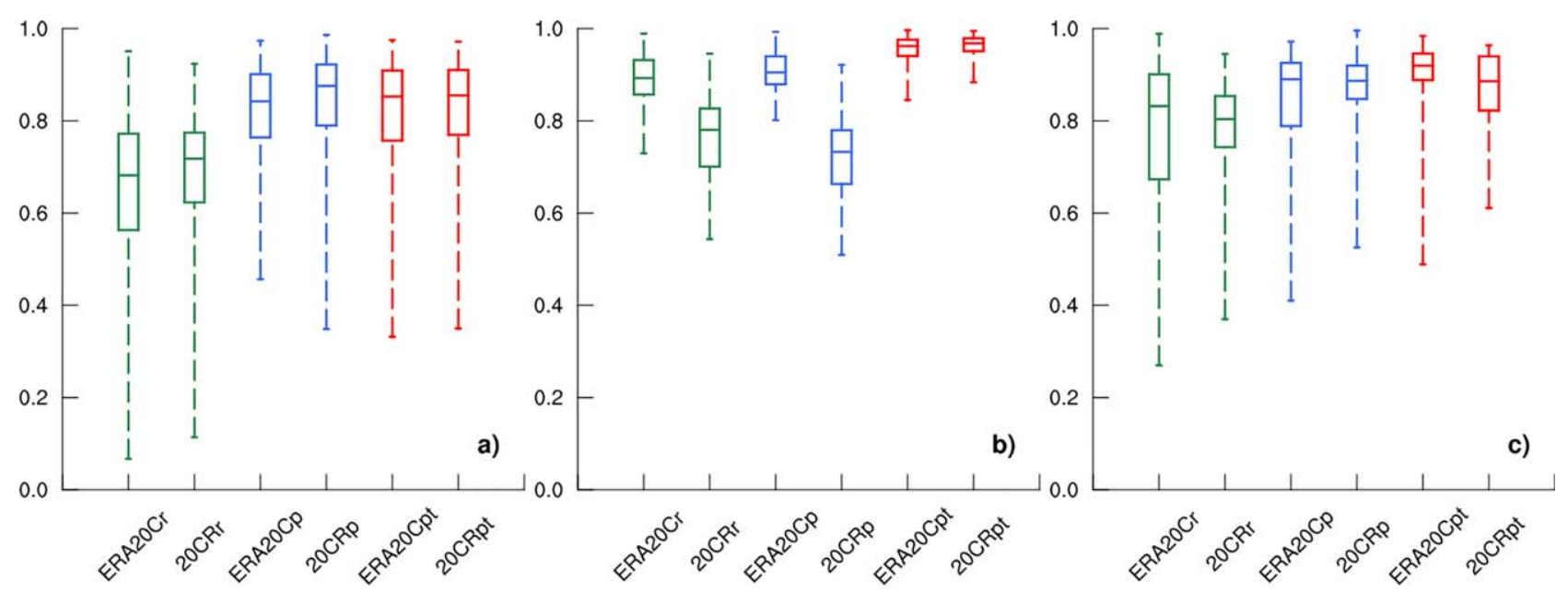

Figure 7. Boxplots of the correlations between annual detrended low-pass filtered series from the reconstructions and the observations for (a) precipitation, (b) temperature, and (c) river flows. For temperature and precipitation, the correlations are calculated on the 1900-2005 period using the SMR data set. For river flows, the correlations are calculated on the longest possible period for each station. All the boxplots in the paper show the minimum/25th centile/median/75th centile/maximum. 

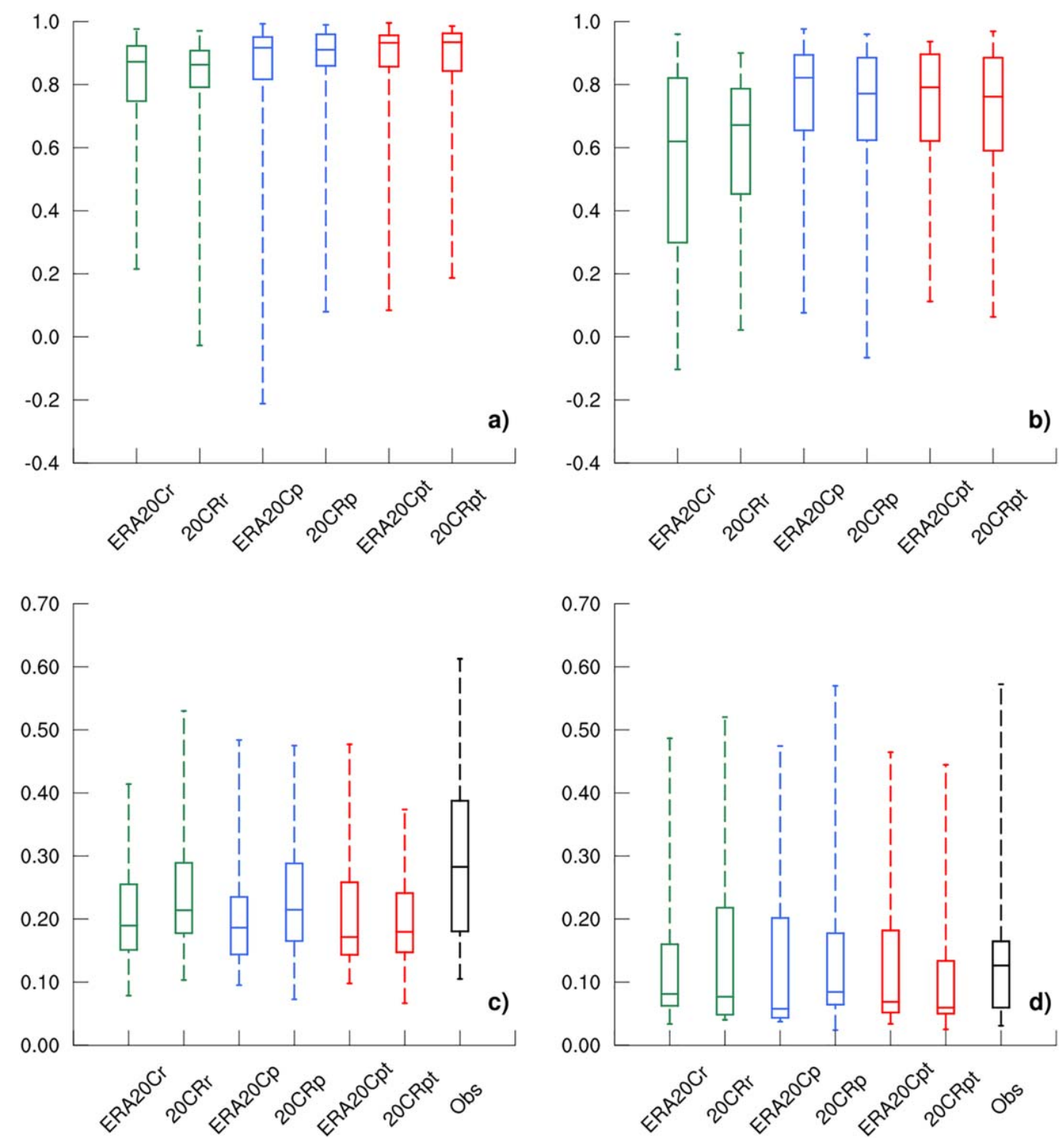

Figure 8. Boxplots of the correlations between detrended and low-pass filtered river flows from the observations and the reconstructions computed on the longest possible period at each stations, in (a) spring and (b) summer. Boxplot of the standard deviation of detrended and low-pass filtered river flows $(\mathrm{mm} / \mathrm{d})$ from the observations and the reconstructions computed on the longest possible period at each stations, in (c) spring and (d) summer.

We now focus on the large hydrometeorological shift between the 1938-1958 and 1965-1985 periods noted in Boé and Habets (2014): the 1965-1985 period is characterized by moister and colder conditions in spring compared to 1938-1958, because of differences in large scale circulation, likely driven by the observed shift from a warm AMV phase to a cold AMV phase. As very similar results are obtained for 20CRpt, only ERA20Cpt results are shown here. The series have been linearly detrended beforehand to remove the potential influence of global warming.

Large changes in river flows are observed for many gauging stations between these periods (Figures 9a and 9b) as shown in Boé and Habets (2014). These variations are especially strong in spring (Figure 9a), when many stations on the Loire and Garonne basins exhibit changes between the two periods as large as $40 \%$. In summer (Figure $9 \mathrm{~b}$ ), there are less gauging stations with strong multidecadal variations than in spring, but some of them still show large changes, up to $40 \%$, for example, over the Pyrenees or the Loire basin. 


\section{QAGU Water Resources Research}
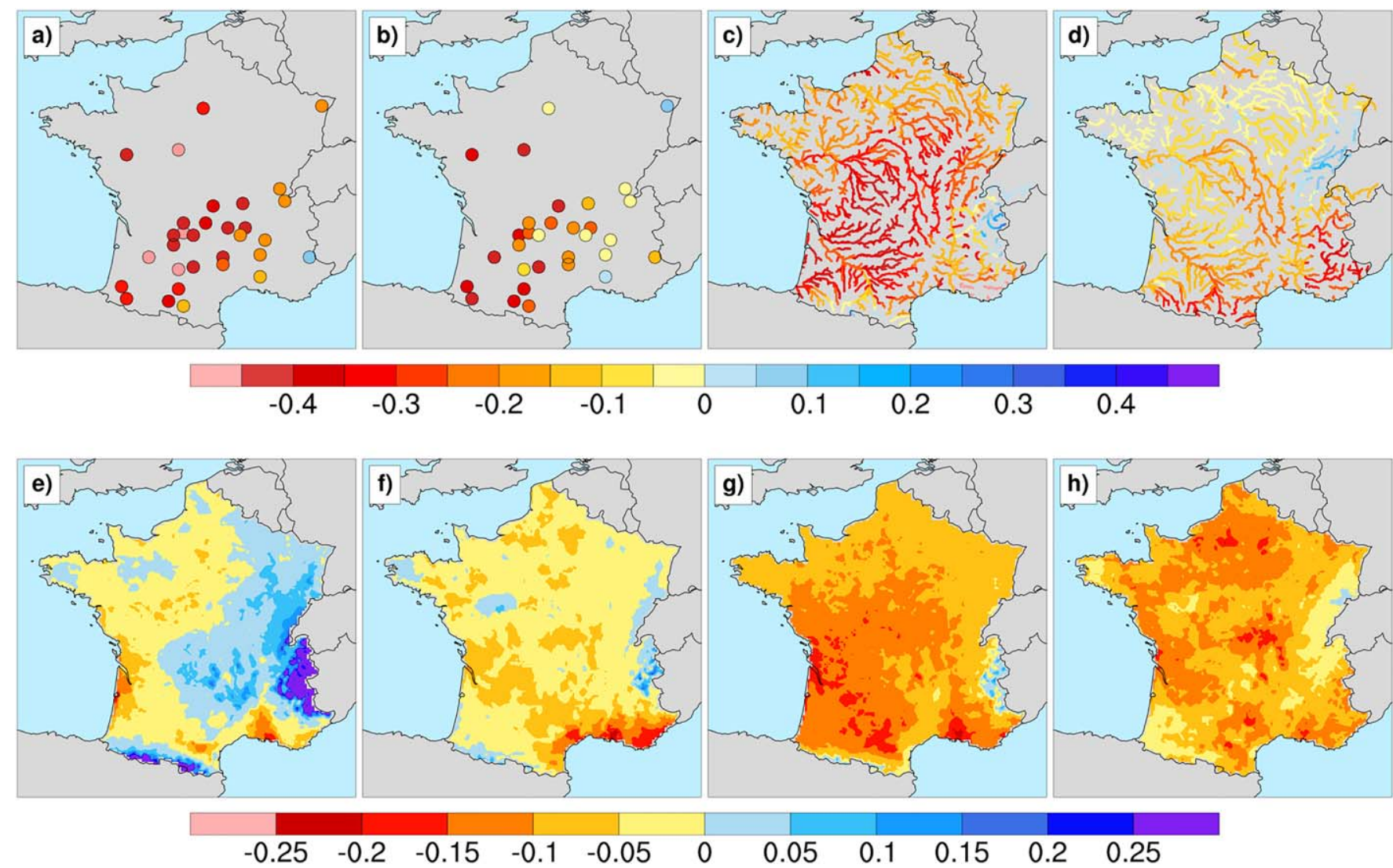

Figure 9. Relative changes between the 1938-1958 and 1965-1985 periods of detrended (a, b) observed river flows, (c, d) simulated river flows, (e, f) evapotranspiration, and $(\mathrm{g}, \mathrm{h})$ soil wetness index (SWI). (a-c-e-g) Spring and (b-d-f-h) summer. Simulated river flows, evapotranspiration, and SWI come from the ERA20Cpt reconstruction. Similar results are obtained with the 20CRpt reconstruction.

The large shift observed in spring is captured by the reconstruction, but is sometimes underestimated, consistently with the previous results (Figures 9a and 9c). In summer (Figures 9b and 9d), three areas in particular show large changes in reconstructed river flows: the Loire, the Pyrenees, and the Southern Alps, with changes as large as $40 \%$ in the mountain areas. These results are generally consistent with the observations in the Pyrenees and for the Loire, although with an underestimation of the changes in the reconstructions. As only one gauging stations is present in the Southern Alps, the changes in the reconstructions cannot be compared to observations there.

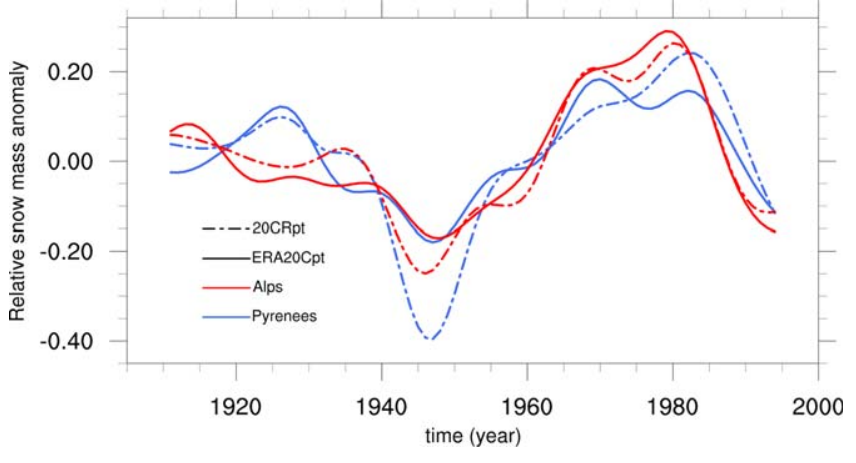

Figure 10. Annual detrended and low-pass filtered relative snow mass anomalies over the Alps (red) and the Pyrenees (blue) (see Figure 1) on 31 May, for the 20CRpt reconstruction (dashed line) and the ERA20Cpt reconstruction (solid line).
Note again that one must remain cautious with the interpretation of the differences between observed and reconstructed river flows at any specific location, as nonclimatic anthropogenic influences such as dams or water abstraction may exist locally, and have particularly important impacts on seasonal variations for some stations. It probably partly explains large differences at some stations between observations and reconstructions seen previously (e.g., the weak correlations shown by the whiskers of the boxplots in Figure 8).

Spring evapotranspiration is larger in the Alps and Pyrenees (up to 30\%) on the 1938-1958 period compared to 1965-1985 (Figure 9e). The larger evapotranspiration in 1938-1958 is very likely caused by the observed negative anomalies in precipitation and positive anomalies in temperature noted by Boé and Habets (2014), that are expected to cause a reduction of the snow cover (as shown later in Figure 10). More bare soil exposed to the atmosphere and the availability of liquid water would then favor 
evapotranspiration on the 1965-1985 period. In summer, the differences in evapotranspiration between 1938-1958 and 1965-1985 over the mountain regions are much more limited.

Large variations of the soil wetness index are seen in spring, notably in the west and in the south of France, and in summer, mainly in the center, the north and south-east of the country, with differences between the two periods close to $15 \%$ (note again that the long-term trend is removed), and consistent with precipitations anomalies (not shown). These large variations may have important implications, for example, for agriculture.

\subsection{Summer River Flows Variations in Mountain Regions and Role of Snow}

The hydrological reconstructions suggest that important multidecadal river flows variations exist in the Pyrenees and in the Alps during summer (Figure 9). However, as shown in Boé and Habets (2014) they cannot be explained by concomitant variations in temperature and precipitation. We noted previously that the large variations in spring evapotranspiration seen in mountain regions (Figure 9e) are likely associated with variations in snow cover. Figure 10 confirms that multidecadal variations exist in snow cover at the end of spring (31 May) over the Alps and Pyrenees. Large (i.e., 15-40\%) negative (positive) anomalies are seen in the 1950s (1970s). The negative snow mass anomalies at the end of spring in the 1950s are likely due to the drier and warmer conditions observed then (Boé \& Habets, 2014), and their impacts on snow accumulation and snow melt.

As the melting of the snow accumulated during winter and spring may be important to sustain summer river flows in mountain regions, these variations of snow very likely explain the variations in summer river flows. It is important to keep in mind that the uncertainties associated with the choice of the atmospheric reanalysis in the variations of snow cover at the end of spring are large, especially for the Pyrenees in the 1950s.

\subsection{Multidecadal Variations in the Loire Basin}

Large multidecadal variations in spring and summer river flows of the Loire are seen both in the observations and the reconstructions (Figure 9), as confirmed in Figures $11 \mathrm{a}$ and $11 \mathrm{~b}$. Their amplitude is smaller in
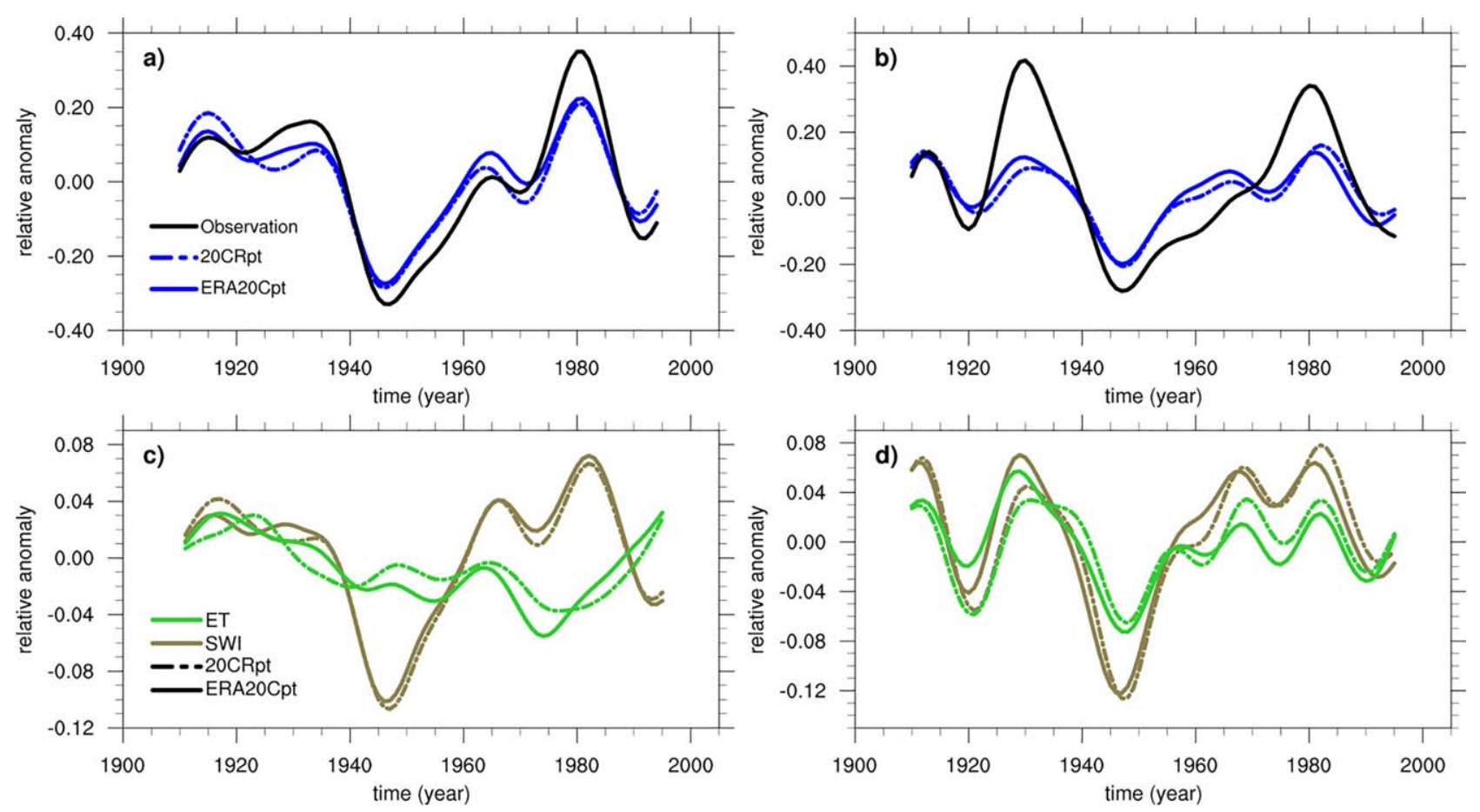

Figure 11. Annual detrended and low-pass filtered relative river flows anomalies from the simulations (blue) and the observations (black) of the Loire at Montjean (see Figure 1), in (a) spring and (b) summer for the 20CRpt reconstruction (dashed line) and the ERA20Cpt reconstruction (solid line). Annual detrended and lowpass filtered evapotranspiration (green) and SWI (brown) of the Loire at Montjean, in (c) spring and (d) summer for the 20CRpt reconstruction (dashed line) and the ERA20Cpt reconstruction (solid line). 


\section{QAGU Water Resources Research}

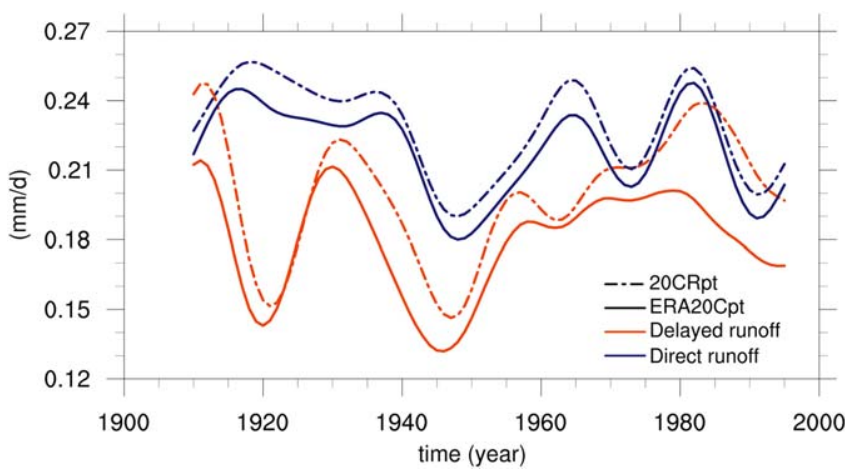

Figure 12. Annual detrended and low-pass filtered relative direct runoff (orange) and delayed runoff (dark blue) of the Loire at Montjean in summer for the 20CRpt reconstruction (dashed line) and the ERA20Cpt reconstruction (solid line). the reconstructions as noted previously, especially in summer. The variations in summer cannot be explained by variations in snow cover as in the Alps and Pyrenees, as snowmelt does not play an important role for this basin.

Variations in precipitation and temperature in spring may impact soil moisture in spring and potentially in summer given the persistence properties of this variable. The variations in summer soil moisture may then impact river flows, for example, by changing the ratio of precipitation in summer that contributes to runoff (Boé \& Habets, 2014). Large negative anomalies in spring soil moisture in the 1950s and large positive anomalies in the late 1970s are seen in the reconstructions over the Loire basin (Figure 11c). The evolution of spring evapotranspiration is largely uncorrelated with the evolution of soil moisture indicating that evapotranspiration does not drive the variations in soil moisture. Precipitation is therefore very likely the main responsible of the variations in spring soil moisture.

Despite the absence of multidecadal variations in summer precipitations and temperatures (Boé \& Habets, 2014), multidecadal variations in soil moisture are also seen in summer, well correlated with the ones seen in spring except that higher frequencies also exist (Figure 11d). The multidecadal variations in summer soil moisture are very likely explained to a large extent by the persistence in summer of the soil moisture anomalies generated in spring by the precipitation variations. Note that this implies that a potential predictability of summer soil moisture anomalies exist.

The soil moisture variations caused by climate variations in spring might therefore partly drive the river flows variations in summer.

Interestingly, strong variations in evapotranspiration very well correlated to those in soil moisture are seen in summer. This positive relationship indicates that the multidecadal variations in summer evapotranspiration are controlled by soil moisture. It is consistent with the idea that evapotranspiration is usually water limited rather than energy limited in this region in summer (e.g., Boé \& Terray, 2008).

Another potential cause of multidecadal variations in summer river flows without concomitant climate variations is the delayed subsurface flow typically associated with aquifers that may help to sustain river flows in summer. MODCOU does not include a representation of aquifers over the Loire basin, and their impact is represented in ISBA with a simple parameterization based on conceptual reservoirs (Artinyan et al., 2008). The contributions of direct runoff and delayed runoff due to reservoirs to total runoff are shown in Figure 12. Both direct and delayed runoffs show negative anomalies in the 1950 s and positive anomalies in the 1970s. Delayed runoff therefore also likely contributes to the multidecadal variations in summer river flows in the reconstructions. Whether this conclusion applies to the real-world remains uncertain, given the large differences between the observations and reconstructions seen in summer (Figure 11b). Incidentally, these differences might be linked to the representation of delayed runoff that is based on a simple conceptual approach on this basin. It is also possible that nonclimatic anthropogenic influences explain, at least partially, the discrepancy between observations and reconstructions for the Loire in summer.

\section{Conclusions}

In this study, a new approach to derive long-term hydrometeorological reconstructions on the twentieth century with a physically based hydrological model is presented. A stochastic statistical downscaling method is applied to long-term atmospheric reanalyses and the results are constrained by monthly homogenized observations to obtain the meteorological forcing necessary for hydrological modeling. The use of observations to constrain the results of statistical downscaling greatly improves the reproduction of monthly to multidecadal variations of precipitation, temperature, and river flows after hydrological modeling. In particular, it allows the unrealistic long-term trends caused by the reanalyses in the results of statistical downscaling to be corrected. The performance of the reconstructions on the twentieth century is stable. The observationally constrained reconstructions provide a valuable data set to study the long-term variations of the hydrological cycle over France. 
The physically based hydrological model used in this study has not been calibrated on observed river flows variations (regarding time scales longer than the month). Observed and simulated river flows are therefore independent. Moreover, the hydrological model does not take into account non climatic anthropogenic influences such as dams or water abstraction. The similarity between observed and simulated river flows therefore shows that the multidecadal river flows variations are generally mainly driven by climate variations. The large multidecadal variations in reconstructed river flows in spring and summer, generally consistent with the observations, therefore confirm that the observed multidecadal variations noted in Boé and Habets (2014) have mainly a climatic origin. The hydrological reconstructions also show that strong multidecadal variations exist in other variables such as evapotranspiration, snow cover, and soil moisture. These variations are generally likely driven by the multidecadal variations of precipitation and/or temperature in spring. The snow cover over the Alps and Pyrenees at the end of spring, available for snowmelt during summer, is modulated by spring precipitation and temperature, with an impact on summer river flows where snowmelt is a significant contributor to climatological river flows. The anomalies in spring soil moisture caused by the multidecadal variations in spring precipitation generally persist in summer, when they may impact evapotranspiration, which tends to be climatologically soil moisture limited over France during summer. The variations in summer soil moisture and in the delayed subsurface runoff also impact summer river flows on some basins.

Even if they are useful, the hydrological reconstructions described in this study are not perfect. The multidecadal variations in simulated river flows are generally very well correlated with the observed ones, but their amplitudes tend to be underestimated in spring, despite the realistic variations in reconstructed precipitation and temperature. Some potential explanations have been put forward, but further work is needed to test them. Moreover, on specific river basins, the important differences associated with the choice of the reanalyses that may exist demonstrate that the observational constraints are not always sufficiently strong to really overcome the differences due to the reanalyses. In any case, reconstructions specific to a river basin could both help to improve the skill of the statistical downscaling method on a region of interest and help to better take into account local observations. It will be the object of future work.

Only precipitation and temperature are used in this study as observational constraints for the meteorological reconstructions but other variables (humidity, wind speed, shortwave, and longwave radiations) are also necessary for hydrological modeling. The lack of long-term observations for these variables does not allow to take them into account in the reconstruction process (nor to assess whether they are correctly represented in the meteorological reconstructions.) This could be an issue for our hydrological reconstructions. For example, Boé (2016) showed that most current climate models tend to simulate a large decrease in summer (and it is also true for other seasons) downwelling solar radiation at surface over western Europe from the early twentieth century to the mid-1970s followed by a positive trend during the global brightening period (Wild et al., 2005). If real, these variations that would necessarily impact potential evapotranspiration, might not be correctly captured by the reconstructions, and impact the realism of simulated lowfrequency hydrological variations. As long-term observations of solar radiation at surface do not exist, this is a delicate issue to deal with. As a first step, we plan to do some sensitivity hydrological experiments by altering the long-term evolution of solar radiation in the meteorological reconstructions, in order to broadly evaluate its potential impact on the long-term evolution of reconstructed river flows. The same approach could be followed for other forcing variables.

Finally, we use monthly rather than daily observations to constrain the results of statistical downscaling because it is a more efficient approach when one is mainly interested by low-frequency variations. However, this methodological choice implies that our reconstructions are not optimal to study floods, including their low-frequency variations. The additional use of daily precipitation observations as a secondary observational constraint to overcome these difficulties will be tested in a future work.

\section{References}

Artinyan, E., Habets, F., Noilhan, J., Ledoux, E., Dimitrov, D., Martin, E., \& Le Moigne, P. (2008). Modelling the water budget and the riverflows of the Maritsa basin in Bulgaria. Hydrology and Earth System Sciences, 12(1), 21-37.

Bellucci, A., Haarsma, R., Gualdi, S., Athanasiadis, P. J., Caian, M., Cassou, C., .. Yang, S. (2015). An assessment of a multi-model ensemble of decadal climate predictions. Climate Dynamics, 44(9), 2787-2806. https://doi.org/10.1007/s00382-014-2164-y

Boé, J. (2016). Modulation of the summer hydrological cycle evolution over Western Europe by anthropogenic aerosols and soilatmosphere interactions. Geophysical Research Letters, 43, 7678-7685. https://doi.org/10.1002/2016GL069394 
Boé, J., \& Habets, F. (2014). Multi-decadal river flow variations in France. Hydrology and Earth System Sciences, 18(2), 691-708.

Boé, J., \& Terray, L. (2008). Uncertainties in summer evapotranspiration changes over Europe and implications for regional climate change. Geophysical Research Letters, 35, L05702. https://doi.org/10.1029/2007GL032417

Boone, A., Masson, V., Meyers, T., \& Noilhan, J. (2000). The influence of the inclusion of soil freezing on simulations by a soil-vegetationatmosphere transfer scheme. Journal of Applied Meteorology, 39(1998), 1544-1569.

Caillouet, L., Vidal, J. P., Sauquet, E., \& Graff, B. (2016). Probabilistic precipitation and temperature downscaling of the Twentieth Century Reanalysis over France. Climate of the Past, 12(3), 635-662.

Compo, G. P., Whitaker, J. S., Sardeshmukh, P. D., Matsui, N., Allan, R. J., Yin, X., .. Brönnimann, S. (2011). The twentieth century reanalysis project. Quarterly Journal of the Royal Meteorological Society, 137(654), 1-28.

Dayon, G., Boé, J., \& Martin, E. (2015). Transferability in the future climate of a statistical downscaling method for precipitation in France. Journal of Geophysical Research: Atmospheres, 120, 1023-1043. https://doi.org/10.1002/2014JD022236

Decharme, B., Boone, A., Delire, C., \& Noilhan, J. (2011). Local evaluation of the Interaction between Soil Biosphere Atmosphere soil multilayer diffusion scheme using four pedotransfer functions. Journal of Geophysical Research, 116, D20126. https://doi.org/10.1029/ 2011JD016002

Decharme, B., Martin, E., \& Faroux, S. (2013). Reconciling soil thermal and hydrological lower boundary conditions in land surface models. Journal of Geophysical Research: Atmospheres, 118, 7819-7834. https://doi.org/10.1002/jgrd.50631

Deser, C., Knutti, R., Solomon, S., \& Phillips, A. S. (2012). Communication of the role of natural variability in future North American climate. Nature Climate Change, 2(11), 775-779.

Deser, C., Phillips, A., Bourdette, V., \& Teng, H. (2010). Uncertainty in climate change projections: The role of internal variability. Climate Dynamics, 38(3-4), 527-546.

Durand, Y., Brun, E., Mérindol, L., Guyomarch, G., Lesaffre, B., \& Martin, E. (1993). A meteorological estimation of relevant parameters for snow models. Annals of Glaciology, 18(1), 65-71.

Goosse, H., Renssen, H., Timmermann, A., Bradley, R. S., \& Mann, M. E. (2006). Using paleoclimate proxy-data to select an optimal realisation in an ensemble of simulations of the climate of the past millennium. Climate Dynamics, 27, 165-184.

Habets, F., Boone, A., Champeaux, J. L., Etchevers, P., Franchisteguy, L., Leblois, E., . . Noilhan, J. (2008). The SAFRAN-ISBA-MODCOU hydrometeorological model applied over France. Journal of Geophysical Research: Atmospheres, 113, D06113. https://doi.org/10.1029/ 2007JD008548

Hawkins, E., \& Sutton, R. (2009). The potential to narrow uncertainty in regional climate predictions. Bulletin of the American Meteorological Society, 90(8), 1095-1107.

Kerr, R. A. (2000). A north Atlantic climate pacemaker for the centuries. Science, 288(5473), 1984-1985. https://doi.org/10.1126/science.288. 5473.1984

Knight, J. R., Allan, R. J., Folland, C. K., Vellinga, M., \& Mann, M. E. (2005). A signature of persistent natural thermohaline circulation cycles in observed climate. Geophysical Research Letters, 32, L20708. https://doi.org/10.1029/2005GL024233

Krueger, O., Schenk, F., Feser, F., \& Weisse, R. (2013). Inconsistencies between long-term trends in storminess derived from the 20CR reanalysis and observations. Journal of Climate, 26(3), 868-874.

Kuentz, A., Mathevet, T., Gailhard, J., \& Hingray, B. (2015). Building long-term and high spatio-temporal resolution precipitation and air temperature reanalyses by mixing local observations and global atmospheric reanalyses: The ANATEM model. Hydrology and Earth System Sciences, 19(6), 2717-2736.

Ledoux, E., Girard, G., \& Villeneuve, J. P. (1984). Proposition d'un modèle couplé pour la simulation conjointe des écoulements de surface et des écoulements souterrains sur un bassin hydrologique. La houille blanche, 1-2, 101-120.

Lorenz, E. N. (1969). Atmospheric predictability as revealed by naturally occurring analogues. Journal of the Atmospheric Sciences, 26(4), 636-646.

Minvielle, M., Pagé, C., Céron, J. P., \& Besson, F. (2015). Extension of the SIM reanalysis by combination of observations and statistical downscaling. In Engineering geology for society and territory (Vol.1, pp. 189-192). Cham, Switzerland: Springer International Publishing.

Martin, E. R., Thorncroft, C., \& Booth, B. B. (2014). The multidecadal Atlantic SST-Sahel rainfall teleconnection in CMIP5 simulations. Journal of Climate, 27(2), 784-806.

Moisselin, J. M., Schneider, M., \& Canellas, C. (2002). Les changements climatiques en France au XXè siècle. Etude des longues séries homogénéisées de données de température et de précipitations. La Météorologie, 38, 45-56.

Noilhan, J., \& Planton, S. (1989). A simple parameterization of land surface processes for meteorological models. Monthly Weather Review, $117(3), 536-549$.

Obled, C., Bontron, G., \& Garçon, R. (2002). Quantitative precipitation forecasts: a statistical adaptation of model outputs through an analogues sorting approach. Atmospheric Research, 63(3), 303-324.

Oliver, E. C. (2015). Blind use of reanalysis data: Apparent trends in Madden-Julian Oscillation activity driven by observational changes. International Journal of Climatology, 36, 3458-3468.

Poli, P., Hersbach, H., Dee, D. P., Berrisford, P., Simmons, A. J., Vitart, F., ... Trémolet, Y. (2016). ERA-20C: An atmospheric reanalysis of the twentieth century. Journal of Climate, 29(11), 4083-4097.

Quintana-Seguí, P., Le Moigne, P., Durand, Y., Martin, E., Habets, F., Baillon, M., .. Morel, S. (2008). Analysis of near-surface atmospheric variables: validation of the SAFRAN analysis over France. Journal of Applied Meteorology and Climatology, 47(1), 92-107.

Sauquet, E., Dupeyrat, A., Hendrickx, F., Perrin, C., Samie, R., \& Vidal, J.-P. (2009). IMAGINE 2030, Climate and water management: Uncertainties on water resources for the Garonne River Basin in 2030? Retrieved from http://cemadoc.irstea.fr/oa/PUB00028876-imagine-2030-climat-amenagements-garonne-quelles-i.html

Terray, L., \& Boé, J. (2013). Quantifying 21st-century France climate change and related uncertainties. Comptes Rendus Geoscience, 345(3), 136-149.

Vidal, J. P., Martin, E., Franchistéguy, L., Baillon, M., \& Soubeyroux, J. M. (2010). A 50-year high-resolution atmospheric reanalysis over France with the Safran system. International Journal of Climatology, 30(11), 1627-1644.

Wild, M., Gilgen, H., Roesch, A., Ohmura, A., Long, C. N., Dutton, E. G., .. Tsvetkov, A. (2005). From dimming to brightening: Decadal changes in solar radiation at Earth's surface. Science, 308(5723), 847-850. 